http://dx.doi.org/10.1590/0102-4698129093

\title{
AMPLIAC̣ÃO DO ENSINO FUNDAMENTAL NA REGIÃO SUL DO BRASIL: PONTOS E CONTRAPONTOS DA PROPOSTA CURRICULAR
}

Zenilde Durli

Marilda Pasqual Schneider*

RESUMO: Este texto procura contribuir com o debate sobre a necessária revisão dos currículos escolares no contexto de ampliação do Ensino Fundamental. São apresentados resultados de um levantamento das especificidades do processo de implantação do Ensino Fundamental de nove anos na rede estadual dos três Estados que compõem a região Sul do Brasil, considerando aspectos normativos implicados na proposta de adequação dos currículos escolares. Destaca, por um lado, o caráter pouco expressivo das orientações emanadas pelas instâncias de regulação intermediária (Conselho Estadual e Secretaria de Educação dos Estados) no processo instituído e, por outro, a atribuição de responsabilidade de revisão curricular aos professores da educação básica, evidenciando (in) congruências nas ações encampadas pelos Estados sulinos.

Palavras-Chave: Ensino Fundamental de nove anos. Processo de implantação. Região Sul do Brasil.

\section{EXPANSION OF THE ELEMENTARY SCHOOL IN SOUTHERN BRAZIL: POINTS AND COUNTERPOINTS OF THE CURRICULAR PROPOSAL}

ABSTRACT: This paper aims at contributing to the debate on the necessary review of school curriculum due to elementary school expansion. It presents results of a survey on the specificities of the nine-year elementary education implementation process in the three Southern States of Brazil's school systems, considering regulatory aspects on the school curriculum adequacy proposal. On one hand, the text highlights the low expressive aspect of the guidelines issued by the intermediate regulatory agencies (State Council and States' Education Secretariat), and, on the other hand, the assignment to basic education teachers the responsibility of reviewing the new curriculum, unveiling the (in)congruencies in the actions established by the southern States.

Keywords: Nine-year elementary school. Implementation process. The South of Brazil.

\footnotetext{
* Doutora em Educação pela Universidade Federal de Santa Catarina (UFSC). Professora da Universidade Federal de Santa Catarina. E-mail: zenildedurli63@gmail.com

* * Pós doutora em Política Educativa pela Universidade do Minho - Portugal. Professora do Programa de Pós-Graduação em Educação da Universidade do Oeste de Santa Catarina (UNOESC).

E-mail: marilda.schneider@unoesc.edu.br
} 


\section{INTRODUĈ̣̃O}

Decretada pelas Leis 11.114, de 14 de maio de 2005 e 11.274, de 6 de fevereiro de 2006, a extensão do Ensino Fundamental (EF) para nove anos não apenas tornou obrigatória a matrícula das crianças aos 6 anos de idade, como também exigiu um conjunto de medidas políticas, administrativas e pedagógicas conducentes aos objetivos almejados. No bojo dessas medidas esteve a discussão sobre a necessidade de adequação dos currículos escolares a propósito de contemplar um ano a mais de EF com entrada aos 6 anos de idade, mas não só. A determinação de ampliação esteve articulada à pretensão de melhoria da qualidade educacional, eleita um dos objetivos majoritários da implantação do Ensino Fundamental de nove anos (EF9A) em todas as escolas brasileiras.

Os discursos oficiais proclamados em textos que forneceram orientações para o processo de transição do EF de oito anos para o EF9A (ver, por exemplo, BRASIL, 2004; 2006), correspondente naquele momento ao tempo de escolarização obrigatória no Brasil ${ }^{1}$, vinculavam a melhoria educacional às condições de elaboração de uma proposta pedagógica conducente à realidade atual, especialmente considerando o tempo de duração do Ensino Fundamental praticado até então pela maioria dos Estados e municípios brasileiros ${ }^{2}$.

No ano da homologação da lei que tornou obrigatória a entrada das crianças no EF aos 6 anos de idade (Lei 11.274/06), o Brasil contava com 33.534.561 alunos matriculados nessa etapa de escolarização. Desse total, 75,8\% estavam concentrados no regime de oito anos. Em 2010, prazo estabelecido pelo governo brasileiro como limite para o início da transição do regime de oito para o de nove anos, havia 31.005.341 alunos matriculados no EF, sendo 66,2\% deles concentrados no EF9A. Significa dizer que, ao término do prazo legal definido para a transição, boa parte das redes de ensino tinha implantado nove anos de Ensino Fundamental.

O percentual de matrículas existente no Ensino Fundamental de oito anos (EF8A) no ano de 2010 demonstrava, porém, uma transição inconclusa. À conta da modalidade de implantação, predominantemente gradativa, adotada pelas redes (SCHNEIDER; DURLI, 2009b), e os anos de 2006 e 2007 como os de início do processo de transição, apenas entre 2011 e 2012 os anos iniciais teriam concluído essa passagem; somente a partir de então os anos finais iniciariam o mesmo processo. Essa constatação justifica o percentual de matrículas ainda remanescente no EF8A, em 2010. 
Em virtude da estratégia de municipalização adotada no Brasil, pós LDB 9.394/1996, que reconhece o município como principal responsável tanto pela educação infantil como pelo Ensino Fundamental, a porção mais significativa das matrículas migradas do EF8A para o EF9A estava, naquele momento, sob a tutela dos municípios.

Com base no exposto, o texto tem por objetivo refletir sobre demandas curriculares às escolas de educação básica com a exigência de implantação do EF9A considerando como campo de estudo o processo instituído na Região Sul do Brasil. O artigo toma como base uma investigação realizada pelas autoras entre os anos de 2012 e 2013 que trata da implantação do EF9A na Região Sul do Brasil e que contou com financiamento do CNPq.

Apesar de reconhecer a predominância de matrículas do EF nas redes públicas municipais de ensino, o estudo tomou apenas a rede estadual dos três Estados sulinos - Paraná, Santa Catarina e Rio Grande do Sul - como campo empírico para o levantamento dos procedimentos e das ações desencadeadas na implantação do EF9A na Região Sul do Brasil. A opção pelas redes estaduais deu atenção às questões de acesso, hipoteticamente mais facilitado aos documentos produzidos, bem como às condições de obtenção de informações mais pontuais sobre o processo vivenciado em cada Estado. Considerou, ainda, o fato de muitos municípios situados na Região Sul se orientarem pelas normas emanadas das instâncias do aparato regulador dos sistemas estaduais - Secretarias de Estado da Educação (SEE) e Conselhos Estaduais de Educação (CEE), condição essa que põe em destaque o papel das instâncias reguladoras intermediárias na implantação do EF9A (BARROSO, 2004).

À conta desses aspectos, compuseram o corpus analítico um conjunto de documentos originados majoritariamente no âmbito destes dois órgãos governamentais - SEE e CEE - no recorte temporal de 2005 a 2011, além de dados estatísticos disponibilizados pelo Inep e informações fornecidas por gestores de cada um dos Estados da Região Sul. ${ }^{3}$

A despeito do recorte geográfico adotado, o estudo considerou a temática do EF9A no contexto mais amplo da reforma da educação conduzida no Brasil nas últimas décadas. De acordo com Oliveira (2010), essa reforma vem sendo arquitetada sob os auspícios do movimento mundial de reestruturação do Estado a partir do qual a intervenção estatal na condução das políticas educativas enseja regulação dos sistemas de ensino públicos pela adoção de novos modos de controle da educação, colmatados preponderantemente 
em pressupostos neoliberais. É objetivo anunciado para justificar as ações que dão sustentação a essa reforma o de assegurar a eficiência e a eficácia do ensino nas escolas.

Pelas razões apresentadas, sustentamos que a ampliação do Ensino Fundamental para nove anos, embora não tenha sido concebida diretamente como uma política curricular, desaguou na necessidade de adequações dos currículos escolares por parte das escolas e redes de ensino não apenas com o objetivo de dar organicidade ao EF9A. As motivações para as mudanças requeridas parecem repousar muito mais sobre a dinâmica do processo de reestruturação do papel do Estado, "enquanto não só um modo de produzir, mas de organizar a sociedade" (OLIVEIRA, 2010, p. 23).

De fato, as reformas educacionais ocorridas na década de 90 sob os auspícios de um Estado que se pauta na avaliação externa como estratégia de regulação e controle da educação básica, tiveram no currículo o centro de uma série de políticas encetadas. Essas políticas estiveram aportadas no discurso da necessidade de mudar a escola e melhorar o padrão de ensino praticado. Não obstante, especialmente no que se refere às mudanças no campo curricular, Goodson (2008, p. 157) evidencia que os efeitos dessas reformas têm sido pouco expressivos na prática visto estarem ancorados predominantemente em uma visão de currículo como "prescrição autoritária".

Apesar de defender que o currículo como prescrição está com seus dias contados, o autor admite que a passagem de um modelo centrado na prescritividade para uma visão mais progressista e emancipadora ainda está longe de ser alcançada, principalmente pela descaracterização da centralidade dos docentes nas decisões curriculares. Consoante enfatiza:

Aqueles velhos tempos em que os profissionais eram autônomos e independentes acabaram: o 'novo profissional' é tecnicamente competente, segue as novas diretrizes e práticas, e considera o ensino como um emprego no qual, como em outros, ele/ela é gerenciado e dirigido e transmite o que lhe pedem que transmita. (GOODSON, 2008, p. 109)

Haja vista o cenário descrito, a análise do processo relacionado à política de ampliação da escolaridade obrigatória na Região Sul do Brasil considerou como pressuposto que, embora produzidos e emanados do poder oficial, os textos legais e orientadores do processo de implantação do EF9A foram produzidos por complexas articulações a partir das quais a participação de múltiplos sujeitos pôs em relação propostas e práticas nem sempre coerentes com os propósitos anunciados. 
O percurso metodológico adotado para a realização da análise pautou-se na abordagem do ciclo de políticas de Bowe e Ball (1992) e Ball (1994). Essa abordagem foi criada por esses pesquisadores como uma metodologia para interpretar políticas educacionais. Ao propor um olhar a partir da ideia de existência de um ciclo no processo de produção e interpretação das políticas sociais e educacionais, os dois autores põem em evidência a necessidade de se considerar diferentes contextos $^{4}$ na análise da trajetória dessas políticas.

Segundo destacam, os textos produzidos a partir das políticas educacionais podem assumir formas variadas: textos normativos, de indicações e/ou orientações, pronunciamentos oficiais, notícias, entre outros. Justamente por serem constituídos a partir da bricolagem de textos produzidos em diferentes contextos, resultam em construções híbridas marcadas pela mistura entre lógicas globais e locais (BALL, 2001).

$\mathrm{Na}$ esteira desses autores, Lopes (2004, p. 112) advoga que os textos produzidos na articulação entre essas dimensões (global elocal), "sejam eles registrados na forma escrita ou não, não são fechados nem têm sentidos fixos e claros". As diferentes intencionalidades político-ideológicas e perspectivas teórico-metodológicas em presença e disputa originam, muitas vezes, textos ambíguos, passíveis de articulações e reinterpretações em múltiplos contextos. Essas reinterpretações conformam o que Bernstein (1996) denomina de recontextualização do discurso pedagógico.

Tomando como referenciais três dos cinco contextos do ciclo de política a que aludem Bowe e Ball (o contexto de influência, o de produção e o da prática), em pesquisas anteriores (SCHNEIDER; DURLI, 2012), observamos a convergência de vários elementos que deságuam na intencionalidade de forjar indicativos curriculares responsivos aos pressupostos de eficiência e eficácia dos sistemas de ensino. Os mais recorrentes relacionam-se à adoção das matrizes de referência de avaliações em larga escala como indicadores privilegiados, quando não únicos, na seleção dos conhecimentos escolares para essa etapa de escolarização. Também tem sido recorrente em algumas redes públicas de ensino a contratação de ONGs e institutos empresariais com o objetivo de adquirir pacotes educacionais prontos, anunciados como soluções eficientes aos problemas do ensino e da aprendizagem. Essas medidas corroboram nossa percepção de que os professores tornam-se, cada vez mais, meros executores de propostas produzidas longe da realidade na qual atuam. 
Frente aos aspectos apontados, tratamos de levantar e analisar, nos documentos oficiais produzidos pelas esferas de governo e nas estratégias utilizadas pelos sistemas estaduais da Região Sul, os elementos convergentes às orientações curriculares emanadas a partir da implantação do EF9A.

Atentos às determinações oficiais que conclamam a autonomia dos estados na condução de políticas para seus respectivos sistemas e às possibilidades de reinterpretação e recriação dos textos da política nacional na adequação ao contexto local (BALL, 1994), buscamos identificar homogeneidades, heterogeneidades e desafios enfrentados pela rede estadual dos três estados no processo de adequação dos currículos escolares ao EF9A. Esses três aspectos são tratados como pontos e contrapontos da proposta de adequação curricular encaminhada pelas esferas administrativas dos estados do Paraná (PR), Santa Catarina (SC) e Rio Grande do Sul (RS) na implantação do EF9A.

\section{ESPECIFICIDADES DA IMPLANTAC̣ÃO DO EF9A NA REGIÃO SUL}

As leis que normatizaram o EF9A em âmbito nacional (11.114 e 11.274) foram exaradas, respectivamente, em 2005 e 2006, sendo que, nos três Estados sulinos, o processo de implantação iniciou entre os anos de 2006 e 2007. A primeira evidência constitui-se, portanto, da imediata adesão ao imperativo federal pelos sistemas estaduais dos Estados. Paraná e Santa Catarina em 2007, e Rio Grande do Sul em 2006.

A pronta adesão às determinações da esfera federal pode ser explicada por argumentos diversos, alguns, inclusive, presentes em textos oficiais. Dentre eles, o de que já havia no país um número significativo de crianças frequentando o EF9A considerando ser essa uma estratégia adotada à época para ampliar receitas. No ano de 2005, do total de matrículas do EF, o Paraná possuía um percentual de 7,64\% no EF9A; Santa Catarina, 8,51\% e Rio Grande do Sul, $14,72 \%$. Desse modo, a ampliação representava um processo em andamento, motivado inicialmente pelo intento de garantir repasse de verbas federais. Nesse contexto, a questão do financiamento erigese como hipótese central nessa imediata adesão ao EF9A.

O discurso da democratização do acesso e da redução das desigualdades sociais pela inserção das crianças pobres na educação obrigatória se configurou como mais um argumento para a implantação imediata do EF9A. Segundo o MEC, a ampliação criaria condições de equidade entre as diferentes procedências sociais. Em 
publicação da Secretaria de Educação Básica (SEB), argumentava-se que essa política consistia em possibilitar um tempo maior de convívio escolar, na perspectiva de aumentar e qualificar as oportunidades de aprendizagem das crianças de seis anos (BRASIL, 2006).

Havia, no entanto, um apelo à imediaticidade de implantação que incluía alguns fatores não divulgados naquele momento, nomeadamente o compromisso do governo brasileiro com organismos internacionais, assumido no início dos anos de 1990 e não realizado, de ampliação da escolaridade obrigatória tendo em vista atendimento às metas educacionais acordadas em âmbito internacional (SCHNEIDER; DURLI, 2012). Essa urgência, tão bem-amparada no discurso oficial, desmereceu como ação necessária, num tempo anterior à ampliação, o lugar da discussão das implicações dessa mudança nos currículos escolares e o tempo necessário para planejar a transição no âmbito dos sistemas, das escolas e das salas de aula.

A natureza genérica das orientações emanadas dos órgãos federais incidiu na produção de textos normativos, no âmbito dos Estados da Região Sul, com a mesma sorte de problemas. Uma das orientações refere-se à imprecisão quanto à data de corte para o ingresso no primeiro ano, o que gerou, no contexto das redes de ensino, polêmicas e disputas de interesses. A imprecisão gerada por normativas e orientações que indicavam, apenas como referência geral, o início do ano letivo, resultou em inúmeras consultas aos Conselhos de Educação dos referidos Estados (CEEs).

$\mathrm{O}$ estudo dos pareceres emitidos à época pelos CEEs demonstrou, na celeuma instaurada, um interesse principal, embora proveniente de fontes diversas. Instituições particulares, sistemas públicos de ensino, escolas, pais faziam consultas ao Conselho Estadual com o intuito de ver ampliado o acesso de crianças com idade cada vez mais precoce no primeiro ano. Para as instituições particulares, por exemplo, a determinação de uma data específica, posteriormente condicionada ao mês de março, restringiu a possibilidade de crianças de 5 anos terem sua matrícula efetivada no EF. Sendo essa uma prática comum da rede privada na implantação do EF9A, a normativa federal impunha restrições significativas.

Essa questão, aparentemente apenas indicativa de um e caminhamento administrativo simples, guarda desdobramentos complexos tanto no trabalho pedagógico como no currículo. O que significa, em termos de planejamento do tempo, do espaço, da seleção dos conhecimentos e da organização do trabalho pedagógico a inserção dessas crianças com idade precoce no EF? 
Os encaminhamentos diferenciados adotados pelos sistemas no que tange à data de corte geraram descontinuidades e reverberaram em outra normativa expedida pelo CNE. A Resolução CNE/CEB 01, homologada em 14/01/2010 que, quatro anos após as primeiras normativas e orientações nacionais acerca do processo de implantação do EF9A, estabeleceu finalmente uma data única para todo o território nacional: "Para o ingresso no primeiro ano do Ensino Fundamental, a criança deverá ter 6 (seis) anos de idade completos até o dia 31 de março do ano em que ocorrer a matrícula" (BRASIL, 2010). O caráter genérico da determinação e a inexistência de diretrizes curriculares orientadoras ao EF9A (exaradas somente em 2010) geraram maior apego às determinações centrais. Embora tenha orientado melhor essa questão da data de ingresso e restringido excessos, a normativa marcou uma das formas de constrangimento das ações desencadeadas a partir das políticas, caracterizada por Barroso (2004) como regulação institucional.

Uma convergência no processo imiscuído refere-se à forma de implantação do EF9A, pois, dentre as opções apontadas, entre a gradativa ou a simultânea, os três Estados sulinos preferiram a primeira (forma gradativa) a partir da qual coexistiram, até o fim do processo de implantação, as duas modalidades de oferta: o Ensino Fundamental com duração de oito anos e com duração de nove anos. Assim, o sistema que implantou o EF9A em 2007, com a primeira série do Ensino Fundamental, integralizou os cinco anos iniciais (até a quinta série/ano do EF9A) em 2011.

A forma de implantação adotada acarretou em percalços para as escolas, sendo o mais expressivo a (re)definição do "que" e "como" ensinar tanto no ano acrescentado como nos demais que compreendem, não só o EF9A, mas também a Educação Infantil e o Ensino Médio. Com o intuito de orientar questões didáticopedagógicas, as SEE dos Estados produziram um conjunto de documentos e materiais norteadores.

No Estado do Paraná, duas iniciativas na direção de orientar e acompanhar a implantação podem ser observadas: (i) a exigência de que os sistemas de ensino apresentassem os projetos de implantação do EF9A aos Núcleos Regionais de Educação, pelos quais se poderia acompanhar o processo nos sistemas municipais e particulares; e (ii) a produção de material contendo diretrizes e orientações pedagógicas para as áreas que compõem o currículo dos anos iniciais.

A Secretaria de Estado da Educação (SEE/PR) disponibilizou ${ }^{5}$, no ano de 2010, um caderno denominado "Ensino Fundamental 
de Nove Anos: orientações pedagógicas para os anos iniciais". Nas notas introdutórias está dito: "foram reunidos professores especialistas de todas as disciplinas curriculares, com o objetivo de possibilitar a reflexão sobre os conhecimentos obrigatórios para esse nível de ensino [...]" (PARANÁ-SEE, 2010, p. 2). De fato, os textos que constituem o documento, referentes às diversas áreas do conhecimento, estão assinados apenas pelos especialistas convidados. Assim, reconhece-se a predominância do trabalho dos especialistas das áreas de conhecimento na elaboração do documento orientador do currículo escolar naquele Estado.

Embora as matrículas no sistema estadual do Paraná privilegiassem os anos finais, em decorrência da quantidade de municípios que optaram por não criar sistemas próprios, vinculando-se ao estadual, a produção das orientações aparece como uma obrigação da Secretaria e uma necessidade dos municípios. Mesmo amparada pelo princípio da autonomia dos municípios na organização de seus projetos pedagógicos, a SEE/PR também reconheceu sua responsabilidade em "orientar as redes de ensino públicas e privadas quanto ao cumprimento da legislação e a organização do trabalho pedagógico" (RPR).

Com procedimentos normativos próximos aos do Estado do Paraná, porém distintos nos encaminhamentos dados pela equipe responsável, o Estado de Santa Catarina publicou a Portaria/SEE 22, ainda em 2006, definindo que as unidades escolares deveriam "rediscutir e adequar seu Projeto Político Pedagógico à nova reorganização do Ensino Fundamental" (SANTA CATARINA, 2006a).

No documento "Orientações para organização e funcionamento das unidades escolares de educação básica e profissional da rede pública", emanado da SEE e veiculado nas escolas (SANTA CATARINA, s/d, p. 2) há menção sobre a organização de eventos junto à rede pública estadual, em parceria com os sistemas municipais, desde então. Conforme consta, esses eventos foram intensificados "em 2006 com a realização de oito encontros mesorregionais, encontros de Comitês Temáticos Regionais e duas videoconferências, culminando com novos seminários nas mesorregionais, em novembro do mesmo ano" (SANTA CATARINA, s/d, p. 2).

A partir de 2008, foram realizados encontros específicos da rede estadual envolvendo especialmente a SEE/SC e as Gerências de Educação (Gereds). Os procedimentos metodológicos inicialmente previstos, especialmente os relativos à revisão dos conteúdos escolares para o EF, contemplavam: (i) indicação de professores representantes de cada série/ano e organização de encontros em cada Gered; (ii) definição 
de representantes de cada gerência para constituir o grupo de trabalho nos encontros por polo; (iii) socialização das propostas dos polos nas respectivas gerências e nas escolas; (iv) indicação de representantes de cada gerência e polo para discussão das propostas com a equipe da SEE; (v) compilação de uma proposta comum para a rede estadual, a partir do que foi construído em cada polo; (vi) socialização da proposta unificada, nas gerências de cada polo e nas escolas.

Para efetivação do trabalho, as Gereds foram agrupadas em sete polos, de modo que, ao final do processo, existiam sete propostas diferentes (SCHNEIDER; DURLI, 2012). Em entrevista concedida em 2011, o Gestor da SEE/SC reiterou esse processo afirmando: "a SEE fez (sic) orientações para as regionais e, junto aos professores do Ensino Fundamental, as discussões foram a partir da Proposta Curricular com consultores organizando uma planilha com os conceitos e conteúdos para cada série. Está em rascunho" (RSC, 2011).

Durante os anos de 2008 e 2009, Gereds e escolas estiveram ocupadas com o trabalho de definição dos conhecimentos escolares para os anos iniciais e finais do Ensino Fundamental e também para o ensino médio, conquanto a implantação do EF9A já estivesse em seu terceiro ano no Estado. Após a construção das propostas nos polos, estava prevista a etapa de consolidação dos documentos por um grupo de sistematização composto por representantes das diferentes gerências. As disputas relativas aos conhecimentos escolares no EF9A impediram a unificação pretendida.

O que não possibilitou, naquele momento, uma unificação do documento foi certo agarramento à autoria, pois cada polo se sentia autor absoluto do seu trabalho, porque acho que os professores fazia muito tempo que não haviam sido envolvidos num processo assim de tanta discussão e, quando eles foram envolvidos, eles tornaram aquilo seu. (RSC, 2011)

Naquele momento, ficou acordado que a SEE/SC faria a consolidação dos conteúdos das áreas/disciplinas de Português e Matemática. Quanto às demais áreas/disciplinas, cada Gered adotaria proposta própria. Em consequência do impasse gerado e também considerando a transição de governo no Estado, a Secretaria manifestou-se novamente sobre o assunto somente no fim de 2011, quando encaminhou às Gereds um documento preliminar para discussão. A proposta que chegou às escolas contou com o trabalho de consultoria externa.

O documento denominado "Orientação curricular com foco no que ensinar: conceitos e conteúdos para a Educação Básica-Documento Preliminar" produzido no âmbito da SEE-SC em 2011, apresenta, 
como objetivo proclamado, aprofundar e qualificar a discussão sobre o currículo para a Educação Básica "com vistas ao desencadeamento da reflexão sobre o tema em todo o âmbito das escolas públicas do Estado de Santa Catarina" (SANTA CATARINA, 2011, p. 4).

Conquanto fosse esse o objetivo da discussão, o EF9A já contemplava o $5^{\circ}$ ano na rede estadual catarinense, último dos anos iniciais, e a definição dos conhecimentos escolares configurava um impasse para muitas escolas nas quais as propostas construídas no âmbito dos polos, nos anos passados, sequer haviam chegado. Até o fim de 2012, ainda não se tinha chegado a um consenso sobre o documento.

Se tanto no Estado de Santa Catarina como no do Paraná o processo de implantação foi marcado por ações pouco expressivas no que tange ao envolvimento de professores na proposta erigida, no Rio Grande do Sul, esse mesmo processo foi peremptório. Informações do representante da SEE-RS dão conta de que a passagem do EF8A para o EF9A naquele Estado teria sido marcada pela inexistência de ações específicas que delimitassem um percurso próprio e autônomo da rede estadual rio-grandense, tendo ocorrido "de forma 'automática', sem desencadear um processo de formação e debate sobre a nova realidade" (RRS).

Não obstante esse posicionamento, os documentos produzidos por aquele Estado evidenciam um percurso complexo e tortuoso de implantação. Arbitrada pelo CEE/RS, principal interlocutor das redes e escolas, a questão foi tratada mais como um problema de gestão burocrática do que propriamente uma questão pedagógica e curricular.

Por meio do Parecer 752, de 26 de outubro de 2005, o CEE/ RS remontou o contexto nacional de mudanças e definiu alguns procedimentos para a implantação do EF9A. Por esse Parecer, definiu que as mudanças na organização curricular deveriam estar limitadas à ampliação de oito para nove anos de duração, sendo incorporadas ao Regimento Escolar pela própria escola. Também determinou às Secretarias de Educação - estadual e municipais - um prazo de 12 meses para que elaborassem os planos para a implementação do EF9A. Os planos deveriam garantir a oferta e a qualidade da educação infantil; organizar os anos iniciais do EF9A; conter a reorganização do tempo e do espaço escolar (mobiliário, equipamentos, acervo bibliográfico e didático); garantir a disponibilidade, capacitação, atualização e formação em serviço dos professores; e prever o processo de avaliação sistemático (RIO GRANDE DO SUL, 2005). Essa determinação foi revogada em 2006 pelo Parecer CEE/RS 644. Vários documentos ${ }^{6}$ foram emitidos na sequência, considerando 
justamente a crítica ao teor excessivamente genérico das orientações e o fato de essas orientações focalizarem questões mais relativas ao disciplinamento da oferta que ao processo pedagógico.

Enquanto o CEE/RS dedicou-se ao disciplinamento da oferta, em 2007, a Secretaria de Estado da Educação do Rio Grande do Sul, em parceria com a União Nacional de Dirigentes Municipais de Educação - Seção Rio Grande do Sul - UNDIME/RS e apoio do escritório Antena da Unesco com sede no Estado, implantou um projeto piloto para alfabetização das crianças de 6 anos. Foram convidadas a participar dessa experiência quatro instituições que, segundo a SEE/RS, teriam reconhecimento em âmbito nacional e comprovada competência na área da educação, especialmente da alfabetização e da avaliação educacional, a saber: Grupo de Estudos sobre Educação, Metodologia de Pesquisa e Ação GEEMPA (RS), Instituto Ayrton Senna (SP), Instituto Alfa e Beto para alfabetização de crianças de 6 e 7 anos (MG) e a Fundação Cesgranrio (RJ). O projeto piloto foi implementado em 550 turmas de escolas estaduais e municipais de 73 municípios. O gestor da rede estadual entrevistado confirma esse processo:

[...] nos anos de 2007, 2008, 2009 e 2010, todo o processo de alfabetização e letramento no RS esteve sob a responsabilidade de institutos contratados para este fim. [...] cada escola através das coordenadorias de educação podia escolher com qual proposta trabalharia. A partir do ano de 2011 iniciou-se um processo de reestruturação curricular nos anos iniciais do Ensino Fundamental.

De acordo com informações fornecidas pelo entrevistado naquele Estado, somente no ano de 2011 ocorreram iniciativas mais abrangentes por parte da SEE/RS, voltadas especialmente aos três primeiros anos do Ensino Fundamental. Uma ação expressiva envolvendo a Coordenadoria de Gestão da Aprendizagem da Secretaria de Estado da Educação do Rio Grande do Sul diz respeito à progressão continuada. A SEE/RS também orientou o planejamento dos professores a partir de áreas de conhecimento, conforme determinam as Diretrizes Curriculares Nacionais para a Educação Básica.

Como se pode constatar, nos três Estados da Região Sul ocorreram algumas iniciativas comuns na condução do processo de implantação do EF9A: produção de normativas pelos conselhos estaduais de educação e também de pareceres acerca das consultas provenientes de sistemas municipais com foco mais acentuado no disciplinamento dos processos de gestão; produção de normativas e documentos orientadores pelas Secretarias de Estado da Educação contendo elementos indicativos da necessidade de discussão dos 
projetos pedagógicos e, neles, das questões curriculares; iniciativas tímidas e pouco expressivas de formação continuada, centradas, basicamente, no estudo dos documentos oficiais e pouco mobilizadas à discussão das questões referentes ao currículo escolar.

As similaridades encontradas nos procedimentos adotados evidenciam que nenhum dos Estados ousou ir além do pretensamente instituído pelo contexto de produção da política. Não obstante as similaridades no processo de implantação, no que tange às orientações para as adequações curriculares, estas tiveram encaminhamentos diversos em cada um dos Estados.

No Paraná, a normativa expedida pelo CEE-PR em 2006 (Deliberação $\mathrm{n}^{-}$03/06) vislumbra elementos que evidenciam a preocupação desse órgão com questões da organização curricular. Acerca das formas de organização do ensino, a referida deliberação determina que o EF9A deverá "organizar-se em ciclos, preferencialmente respeitando-se outras formas de organização estabelecidas no Art. 23 da LDB, sempre que o interesse do processo de aprendizagem assim o recomendar [...]" (PARANÁ-CEE, 2006). Essa indicação ganha maior relevância nos anos iniciais, em razão da progressão continuada para os anos que compõem um mesmo ciclo. Nas normativas nacionais, o objetivo explícito dessa política se vincula à redução dos índices de repetência que assombram o país, especialmente nessa etapa da escolaridade básica.

Em relação aos conhecimentos escolares considerados válidos, a Deliberação 03/06 orienta que: "não representem a transferência dos conteúdos e atividades da atual $1^{\underline{a}}$ série para as crianças de 6 anos de idade, mas concebam uma nova organização dos conteúdos em um Ensino Fundamental de 9 (nove) anos" (PARANÁ-CEE, 2006). Além de apontar a necessidade de um novo currículo com indicação de conteúdos específicos para cada ano; de organização do tempo e do espaço escolar, com todo o aparato de mobiliário, equipamentos e materiais pedagógicos compatíveis às crianças de 6 anos, o documento do Estado do Paraná repete documentos produzidos na esfera federal. Destaca, ainda, elementos a serem considerados na elaboração da proposta pedagógica, corroborando, também nesse aspecto, orientações nacionais. Dentre os elementos destacados no referido documento estão: as concepções de infância, de desenvolvimento humano e de ensino e aprendizagem; o contexto da população e da comunidade; a descrição do espaço físico, instalações e equipamentos, dentre outros constantes em documentos disponibilizados pelo MEC no mesmo período. A normativa delibera na direção de um processo 
avaliativo sem caráter seletivo, o que remete à progressão automática, não denominada desse modo, mas presente nas orientações nacionais (BRASIL, 2004) como sendo a mais indicada às redes e sistemas de ensino (PARANÁ-CEE, 2006).

Seguindo as prerrogativas do CEE, a Secretaria de Estado determinou a elaboração da proposta pedagógica definindo "conteúdo, metodologia e avaliação dos anos iniciais em consonância com as orientações da mantenedora” (PARANÁ-SEE, 2006, p. 1). Depois de concluída, a proposta deveria ser encaminhada ao Núcleo Regional de Educação de sua jurisdição até o início do ano letivo de 2007 a que caberia a tarefa de analisar e validá-las, a partir dos parâmetros delimitados pelo CEE/PR (PARANÁ-SEE, 2006).

Verifica-se, desse modo, que no Estado do Paraná houve coerência entre as orientações emanadas do CEE e as da SEE, e que ambas estavam plenamente harmonizadas com as orientações nacionais. Em relação tanto à estrutura quanto à questão pedagógica, constatamos preocupação destes dois órgãos (CEE e SEE) com a adaptação da escola para a recepção da criança com 6 anos de idade. Como indicativo, há o fato de que, nas questões pedagógicas, a ênfase foi posta na inclusão da brincadeira e dos brinquedos como ferramentas pedagógicas para ensinar e aprender.

Em Santa Catarina, as primeiras normativas expedidas pelo SEE/SC, nos anos de 2005 e 2006, atribuíram ás unidades escolares a tarefa de revisão curricular, definindo que estas deveriam rediscutir o projeto pedagógico "respeitando a concepção de educação, escola, infância e criança, materializada nos pressupostos da Proposta Curricular de Santa Catarina/1998, no documento Estudos Temáticos/2005 e nas Diretrizes Curriculares Nacionais" (SANTA CATARINA, 2006d).

Em 2009, a SEE/SC ratificou o entendimento explicitado nas normativas nacionais de que o processo de alfabetização com letramento não deveria estar circunscrito à $1^{\underline{a}}$ série, estabelecendo dois momentos para a organização curricular dos anos iniciais: i) "momento inicial da aprendizagem da leitura e escrita" compreendendo os três primeiros anos do EF9A envolvendo as crianças de 6, 7 e 8 anos de idade; ii) "momento intermediário de complexificação das habilidades de ler e escrever" organizado nos dois anos subsequentes com as crianças de 9 e 10 anos de idade. Recomenda, para o primeiro momento, o planejamento de um "processo de aprendizagem das habilidades de leitura e de escrita com a duração de três (3) anos em um continuum pedagógico, sem interrupção" (SANTA CATARINA, 2009 , p. 8 - grifos no original). 
Foi dada prioridade às áreas de Língua Portuguesa e Matemática como diretriz para organização dos conhecimentos escolares nos três primeiros anos do EF. Ainda que o termo não tenha sido explicitado, a orientação emanada encaminhou à definição de dois ciclos para os anos iniciais: $1^{\circ}, 2^{\circ}$ e $3^{\circ}$ anos compondo o primeiro ciclo; $4^{\circ}$ e $5^{\circ}$ anos o segundo ciclo. Recomendou, por essa via, a progressão continuada dentro dos ciclos com especial destaque ao primeiro.

A par dessa normativa, durante os anos de 2008 e 2009, as Gereds estiveram ocupadas com o trabalho de definição dos conteúdos para os anos iniciais e finais do Ensino Fundamental e também para o Ensino Médio, em processo arbitrado pela SEE/SC conquanto a implantação do EF9A já estivesse em seu terceiro ano no Estado. Em 2010, tendo em vista a homologação das Diretrizes Curriculares Nacionais Gerais para a Educação Básica, pela Resolução 4, de 13 de julho de 2010, e Diretrizes Curriculares Nacionais para o Ensino Fundamental de nove anos, pela Resolução no 7 , a atenção acerca das alterações curriculares na rede estadual catarinense voltouse ao estudo dessas normativas federais.

Somente no mês de setembro de 2011 a SEE/SC disponibilizou às escolas e Gereds documento preliminar orientando sobre procedimentos a serem adotados no que concerne às adequações curriculares. Entendido como a síntese do processo de discussão e construção de uma proposta para o EF9A, o documento "Orientação curricular com foco no que ensinar: conceitos e conteúdos para a Educação Básica - Documento Preliminar" (SANTA CATARINA, 2011) anuncia, logo na apresentação, o objetivo de "aprofundar e qualificar a discussão sobre currículo para a Educação Básica, com vistas ao desencadeamento da reflexão sobre o tema em todo o âmbito das escolas públicas do Estado de Santa Catarina" (SANTA CATARINA, 2011, p. 4).

Conquanto o objetivo fosse o de promover a discussão, o EF9A já contemplava o $5^{\circ}$ ano do Ensino Fundamental na rede estadual, último dos anos iniciais, sendo a definição dos conteúdos escolares um hiato para muitas escolas nas quais as propostas construídas no âmbito dos polos, nos anos anteriores, nem sequer haviam chegado. Também ficou declarada a intencionalidade de tratar o currículo com foco nas experiências e nos conhecimentos escolares.

No terceiro item do documento disponibilizado em 2011 consta a definição dos conhecimentos para os primeiros cinco anos do EF. Nesse item, especificamente, observa-se um esforço da SEE catarinense em demonstrar a vinculação da proposição com 
os referenciais dos cadernos da Proposta Curricular catarinense, publicados em 2001 e 2005. Nos trabalhos desenvolvidos em 2008 e 2009 pelas Gereds houve empenho deliberado dos grupos de trabalho em determinar conhecimentos básicos para todas as áreas/disciplinas da Base Comum Nacional. Porém, não sendo alcançada a pretendida unificação das propostas naquele momento, ficou acordado que haveria uma tentativa de aproximar, o máximo possível, ao menos os conteúdos de matemática e língua portuguesa.

Outras razões, no entanto, podem igualmente ter conclamado tal decisão. Concomitante à política de ampliação da escolaridade obrigatória, textos emanados do $\mathrm{MEC}$ e do $\mathrm{CNE}^{7}$ indicam a prioridade da alfabetização e do letramento juntamente com o domínio das operações matemáticas básicas como o conhecimento escolar destinado ao ensino nos três primeiros anos do EF9A. Tal orientação pode ser observada logo na página 10 do documento preliminar, no qual há menção às "expectativas de Aprendizagem na Educação Básica" que vêm sendo trabalhadas pelo CNE e assumidas como indicativo para a definição dos conhecimentos escolares válidos aos três primeiros anos de escolaridade, conforme segue: "acesso e consolidação das habilidades essenciais de leitura, escrita e cálculo" (SANTA CATARINA, 2011, p. 10).

Na parte dedicada aos anos iniciais, são tecidas considerações sobre o processo de avaliação e apresentados descritores que deveriam servir como guia norteador às avaliações e seleção do que seria trabalhado durante o ano letivo. Mais adiante, pode-se ler a seguinte afirmação: "Alguns dos descritores, apresentados neste eixo, foram retirados ou adaptados da matriz de referência de avaliação em alfabetização e letramento da Provinha Brasil e da Prova Brasil, outros foram capturados das propostas apresentadas pelos polos" (SANTA CATARINA, 2011, p. 32). Uma nota de rodapé na página 35 informa que houve consulta à matriz de referência de matemática do Saeb - Prova Brasil. Além da inconteste vinculação com as avaliações em larga escala, causa estranheza, quando observada a forma de organização dos conteúdos para os anos iniciais, a desarticulação com o proposto pelos grupos de trabalho dos polos regionais nos anos de 2008 e 2009.

Nas 68 páginas seguintes consta a "Proposta Preliminar de Conceitos e Conteúdos para as séries finais do Ensino Fundamental e o Ensino Médio". Na introdução estão apresentados os fundamentos legais com destaque para as Diretrizes Curriculares Nacionais para a Educação Básica (DCNEB), as Diretrizes Curriculares Nacionais para 
o Ensino Fundamental e as Diretrizes Curriculares Nacionais para o Ensino Médio, enfatizando nelas a indicação de organização curricular em áreas do conhecimento, recomendando ênfase em Linguagens, Matemática, Ciências da Natureza e Ciências Humanas. Dentro de cada área são definidas as disciplinas e, para essas, delimitados quadros com dois grandes eixos: conceitos e conteúdos. Os conceitos estabelecidos são os mesmos para todos os anos finais e também para o ensino médio. Os conteúdos estão definidos para cada ano.

$\mathrm{Na}$ delimitação dos conceitos erigidos no Documento de 2011 está nitidamente apontada a intencionalidade de manter a mesma lógica que orienta a PC/SC, nomeadamente o caderno de 2001 da PC. A organização dos conteúdos por áreas de conhecimento preconizada pelas DCNEB e ratificada no Documento de 2011 parece apenas cumprir o requisito legal, uma vez não haver indicativos metodológicos orientadores do trabalho docente que justificasse essa organização.

A análise do percurso instituído na rede estadual catarinense, bem como o estudo do Documento Preliminar publicizado em 2011, permite constatar que o processo de revisão da PC/SC em curso apresenta especificidades contextuais que a afastam dos pressupostos teóricos originais. Essas especificidades são produzidas tanto em contexto nacional quanto local. As normativas nacionais que orientam a reforma carregam os contornos da política educacional produzida no cerne de um Estado neoliberal e, portanto, ultimadas pelos princípios da eficácia e eficiência nos sistemas de ensino. As avaliações em larga escala, instrumentos construídos a partir dessa lógica, também representam um instrumento de restrição e controle aos sistemas por exigir resultados alinhados a desempenhos considerados adequados às estatísticas nacionais e internacionais.

Diversos elementos estiveram implicados e influenciadores dos encaminhamentos adotados. Dentre eles, destacam-se a inexpressiva participação dos professores no processo de revisão curricular e a falta de formação continuada articulada aos pressupostos da PC como indicativos das dificuldades encontradas para alinhar a proposta erigida aos princípios inspiradores das propostas curriculares anteriores e das disputas epistemológicas, conduzidas por forças provenientes dos grupos envolvidos, quais sejam: professores, especialistas das áreas/ disciplinas, consultores externos, técnicos da SEE/SC, sistemas de regulação adotados pelo poder central.

No caso do Rio Grande do Sul, as análises realizadas sobre o processo desencadeado para a revisão dos currículos evidenciam que a mudança do EF8A para o de 9 anos na rede estadual ocorreu de 
sobressalto não só para os estabelecimentos de ensino, mas, também, para o CEE/RS - órgão fiscalizador, deliberativo, consultivo e normativo do Sistema Estadual de Ensino. O expressivo número de documentos abordando as mesmas questões, com pequenas retificações, é forte evidência do fato. As dúvidas levantadas pelos estabelecimentos de ensino e encaminhadas ao CEE/RS, desde 2006, com frequência regular nos anos subsequentes, evidenciam falta de clareza e de detalhamento das normativas, bem como ausência de espaços de discussão e formação aos gestores e professores das redes de ensino.

Não encontramos registros documentais, emanados da $\mathrm{SEE} / \mathrm{RS}$, acerca de formação coletiva aos professores da rede ou de discussões que envolvessem as questões curriculares no contexto de implantação do EF9A. No questionário respondido, RRS confirma não ter havido participação dos professores nas decisões tomadas, tampouco formação continuada. A iniciativa principal da SEE/RS foi a de "firmar contrato com empresas tendo em vista implantar experiências diversificadas de alfabetização e letramento." (RRS)

Foram contratadas quatro propostas diferentes no Estado riograndense. Cada escola poderia optar pela proposta com a qual desejava trabalhar. A iniciativa da SEE/RS foi, portanto, em um primeiro momento, a de terceirizar as discussões e os encaminhamentos do currículo escolar em um processo no qual houve espaços formativos aos professores, porém, na direção de assumirem, como executores, propostas concebidas fora do contexto das escolas e sem a participação daqueles que seriam os agentes da implantação.

Os dados levantados informam que a atenção da SEE/RS esteve centrada nos três primeiros anos do EF9A. Essa constatação é reafirmada em novembro de 2011, quando, acatando as indicações do CEE/RS (Parecer Normativo 427/2010; Parecer 194/2011), a SEE/ RS definiu a progressão continuada para os três primeiros anos do EF. Em Ofício Circular encaminhado às Coordenadorias Regionais de Educação, datado de 8 de novembro de 2011, que orienta sobre a progressão continuada, a SEE/RS determina para as escolas: "alterar regimentalmente esse item no ano de 2011 e propor novas alterações em 2012 em função do "Ano da Reestruturação curricular", que adequará todas as dimensões regimentais às novas definições legais" (RIO GRANDE DO SUL, 2011). Para além do que significa essa orientação, destacamos que, para a rede estadual de ensino, o ano de 2012 seria o "Ano da reestruturação curricular". Passados seis 
anos desde a implantação do EF9A no Estado, após a transição dos anos iniciais ter sido concluída, as iniciativas de formação e revisão curricular finalmente começam a ser organizadas.

Considerando a trajetória promovida, concebemos ter predominado no Estado do Rio Grande do Sul um modelo tortuoso, verticalizado e burocrático de implantação do EF9A, creditado em boa medida pela extensiva produção de documentos oficiais expedidos especialmente pelo CEE/RS. Reproduzindo as normativas federais, esse órgão gerou a mesma sorte de problemas, consequentes de orientações vagas e genéricas emanadas do poder dos órgãos federais e por ter de reformular inúmeras vezes a orientação sobre um mesmo ponto.

Porquanto não chegamos a analisar a efetividade dos encaminhamentos adotados, não é possível dimensionar o grau e as formas de resistência no Estado rio-grandense. É possível afirmar, no entanto, que as forças em disputa estiveram representadas pelo poder central, talvez menos pelas normas e mais pelas injunções decorrentes das cobranças acerca da eficiência e eficácia no processo de alfabetização das crianças. A atenção da SEE/RS, concentrada nos três primeiros anos, inicialmente com a terceirização do currículo escolar e, em 2012, na criação de um programa de formação continuada aos professores dos três primeiros anos do EF e adesão ao Pacto Nacional pela Alfabetização na Idade Certa (PNAIC), ratifica essa vinculação.

$\mathrm{Na}$ busca pela receita de sucesso, nos primeiros anos da implantação da ampliação da escolaridade obrigatória de oito para nove anos, no RS, empresas, institutos e demais organizações que vendem pacotes prontos disputaram o espaço de discussão e definiram os currículos escolares para os anos iniciais. Somente em período mais recente as iniciativas se voltaram à formação dos professores, embora ainda restrita aos três primeiros anos do EF9A.

Chama a atenção o movimento de terceirização das questões pedagógicas e curriculares. Nessa situação, a autonomia das escolas é apenas aparente, pois é regulada pela oferta de projetos predeterminados. O professor, excluído de pensar o processo pedagógico, figura como consumidor de propostas e currículos prontos. A inexistência de um projeto de formação continuada aos professores da rede, especialmente em relação às questões curriculares ensejadas pela ampliação da escolaridade obrigatória, acolhe e reforça a crença em uma profissionalidade destituída do pensar e partilhar decisões políticas e pedagógicas inerentes à docência. 
A partir da trajetória efetuada em cada um dos Estado sulinos, podemos concluir que os encaminhamento no processo de transição do EF8A para o EF9A, mesmo constrangidos pela força da regulação institucional por reproduzirem, ipsis verbis, normativas do poder central, inclusive com a mesma sorte de problemas, foram marcados por procedimentos singulares.

No que tange às especificidades, no Paraná, a SEE/PR destacou o papel dos especialistas na produção de orientações acerca dos conteúdos curriculares. Essa orientação é balizada na prerrogativa de autonomia dos sistemas, por essa razão, tanto a SEE/PR quanto o CEE/PR delegaram aos municípios a condução do processo.

A iniciativa empreendida pelo Estado de Santa Catarina é a que, a nosso ver, distingue-se, em alguma medida, das demais empreendidas. Apesar dos problemas que a proposta curricular erigida possa oferecer, em termos teórico-metodológicos e de orientações para as escolas, uma vez assente no delineamento pouco preciso de conceitos, procedimentos e conteúdos, ressaltamos o fato de a SEE ter procurado desenvolver um processo participativo de discussão, envolvendo professores, gestores, representantes de escolas e das instâncias intermediárias (Gereds) na produção de um documento que, mesmo aparentemente, representasse a síntese do desejo da rede estadual na consecução dos currículos das escolas.

Não obstante, o documento resultante desse processo ainda inconcluso permite observar diferentes fontes de influência tensionando concepções de educação e currículo. Dentre elas, destacamos: o texto da proposta curricular do Estado, construída desde os anos 80, erigida sobre o aporte da concepção históricocultural; a definição de alguns conteúdos, especialmente de língua portuguesa e matemática, segundo o que estabelecem as matrizes de referência das avaliações em larga escala; a participação de consultores externos ao sistema, especialistas nas disciplinas/áreas; a influência dos documentos normatizadores e orientadores emanados dos órgãos do poder oficial em suas diversas instâncias; a proposta construída em cada um dos polos entre os anos de 2008 e 2009.

No Rio Grande do Sul, o CEE encabeçou o processo de revisão dos currículos e ordenou a sua execução. A SEE ocupou-se em terceirizar as questões curriculares, sendo, portanto, a nosso ver, a iniciativa mais arbitrária dentre os três Estados. Nos poucos documentos da SEE/ RS disponíveis, pudemos identificar, como forças disputando questões relativas ao currículo, as empresas educacionais e ONGs, as orientações contidas nos textos normativos e de orientações provenientes do poder 
central e, por derradeiro, as resistências que devem ter existido nas escolas nas quais as propostas foram implantadas.

Conclusivamente, podemos afirmar que, embora varie na forma, a trajetória empreendida em cada um dos Estados evidencia tendência ao que Ball (2001) denomina de processo de "bricolagem" na produção de políticas educacionais. A compreensão desse processo implica considerar que as políticas são resultado de um nexo de influências criado pelo "empréstimo e [pela] cópia de fragmentos e partes de ideias de outros contextos, de uso e melhoria das abordagens locais já tentadas e testadas" (p. 102). Constituem, por isso, textos híbridos, que combinam diferentes lógicas nem sempre congruentes entre si. Em se tratando de bricolagem de textos, parece que Santa Catarina é o exemplo mais emblemático dos encaminhamentos adotados pelos Estados sulinos.

\section{CONSIDERACְ̃̃ES FINAIS}

O estudo permitiu evidenciar que os desdobramentos da política de ampliação do Ensino Fundamental, produzida pelo poder central nos sistemas de ensino dos Estados que compõem a Região Sul, foram intermediados, em sua extensiva maioria, pelos Conselhos Estaduais de Educação e Secretarias de Estado da Educação de cada um dos entes federados. No processo instituído predominou a reprodução dos textos normativos e de orientação nacionais como princípio balizador da proposta de implantação adotada pela rede estadual de cada um dos Estados sulinos, ainda que tensionado pelas relações entre contextos macro e microssocial. Como consequência, tais procedimentos geraram o mesmo tipo de celeuma que orientou o processo de implantação em contexto nacional como, por exemplo, a polêmica sobre a idade de corte para o ingresso no EF9A.

Em relação à proposta curricular, o caráter arbitrário das orientações emanadas dos Estados, de um lado, e a incorporação dessas mesmas esferas às forças regulatórias nacionais, por outro, sem o devido tensionamento da realidade de cada um dos entes federados, resultaram em indicações que são, a um só tempo, polarizadas na orientação, mas pouco expressivas na sua constituição textual.

Essa constatação vem sustentada no fato de que nenhum dos três Estados chegou a apresentar, de forma objetiva e prática, uma proposta curricular para a rede, preferindo atribuir essa responsabilidade às escolas ou aos sistemas municipais (no caso do Paraná), porém sem o devido preparo dos professores a quem se 
atribui a responsabilidade de protagonizar uma ampla e profunda reforma curricular. Tal fato põe em evidência as fragilidades na superação dos programas tradicionais praticados no modelo anterior, quando as crianças entravam na escola com 7 anos de idade.

A reprodução, ipsis verbis, de algumas normativas oficiais do âmbito federal, por um lado, e a forma imprecisa e pouco consistente de alguns textos produzidos no âmbito dos estados, por outro, permitiu verificar o movimento da política nacional no contexto dos estados subnacionais pondo em evidência certo privilégio do contexto de influência da política educacional na articulação entre o contexto macro e micro. Especificamente em relação a esse movimento, foi possível constatar, ainda, que o processo de implantação do EF9A na Região Sul deu-se em um campo complexo e contraditório, permeado, a um só tempo, por lutas, acordos, negociações e imposições. Essas características espelham as tensões da historicidade política, educacional e social em que vivemos atualmente.

No terreno dos desafios, persiste a necessidade de um processo amplo de discussão acerca de uma necessária reforma curricular que contemple a educação básica, debate esse que não pode prescindir da participação e do envolvimento de todos os professores, de modo a contribuir, inclusive, na formação continuada desses profissionais, aspecto esse praticamente ignorado no processo desencadeado no âmbito dos Estados aqui analisados.

Encerrado o processo de implantação nos anos iniciais, intensifica-se a necessidade de se observar cuidadosamente os anos finais, de modo a se evitar cometer os mesmos equívocos. Tendo as escolas estaduais da Região Sul iniciado, em 2013, a transição em relação à terminalidade do Ensino Fundamental, vislumbramos como desafio assegurar espaços de debate e reflexão também nos anos finais. Esse processo necessita, a nosso ver, considerar a experiência nos anos iniciais como elemento importante no encaminhamento da implantação do EF9A nos anos finais do Ensino Fundamental.

\section{REFERÊNCIAS}

BALL, S. J. Diretrizes políticas globais e relações políticas locais em educação. Currículo Sem Fronteiras, v. 1, n. 2, p. 99-116, jul./dez. 2001.

. Some refletions on policy theory: a biref response to Hatcher and Troyna. Journal of Education Policy, London, v. 9, n. 2, p. 171-182, 1994.

BARROSO, J. Os novos modos de regulação das p olíticas educativas na Europa: da regulação do Sistema a um Sistema de regulações. Educação em Revista, Belo Horizonte, n. 39, p. 19-28, jul. 2004. 
BERNSTEIN, B. A estruturação do discurso pedagógico: classe, códigos e controle. Petrópolis: Vozes, 1996.

BOWE, R. BALL, S. Reformig eduation and changing schools: case studies in policy sociology. London: Routledge, 1992.

BRASIL. Ministério da Educação. Secretaria de Educação Básica. Ensino Fundamental de Nove Anos - Orientações Gerais. Brasília, 2004. Disponível em: <http://portal.mec.gov.br/seb/ arquivos/pdf/Ensfund/noveanorienger.pdf>. Acesso em: 14 nov. 2013.

BRASIL. Ministério da Educação. Secretaria de Educação Básica. Ampliação para o Ensino Fundamental para nove anos: relatório do programa. Brasília 2004. Disponível em: <http:// portal.mec.gov.br/seb/arquivos/pdf/9anosrelat.pdf> Acesso em: 15 set. 2013.

BRASIL. Notícias da Secretaria de Educação Básica do MEC. FERNANDES, Francisco das Chagas. Política de ampliação do Ensino Fundamental para Nove Anos - pela inclusão das crianças de seis anos de idade na educação obrigatória. Brasília, 2006. Disponível em: $<$ http://portal.mec.gov.br/seb/arquivos/pdf/Ensfund/chagas_ensfundnovanos.pdf > . Acesso em: 11 maio 2013.

BRASIL. CNE. Resolução n. 1, de 14 de janeiro de 2010. Define Diretrizes Operacionais para a implantação do Ensino Fundamental de 9 (nove) anos. Diário Oficial da União. Seção 1. n. 10, de 15 de janeiro de 2010.

DURLI, Z.; SCHNEIDER, M.P. O ensino fundamental de nove anos: desafios à formação de professores. In: Revista Retratos da Escola. Brasília, v. 4, n. 7, p. 329-340, jul./dez. 2010.

GOODSON, I. F. As políticas de currículo e de escolarização: abordagens históricas. Petrópolis, RJ: Vozes, 2008.

LOPES, A.C. Políticas curriculares: continuidade ou mudança de rumos? Revista Brasileira de Educação. N. 26, Maio /Jun /Jul /Ago 2004.

MAINARDES, J. Abordagem do ciclo de políticas: uma contribuição para a análise de políticas educacionais. Educação e Sociedade, Campinas, v. 27, n. 94, p. 47-69, jan./abr. 2006.

MAINARDES, J. Reinterpretando os ciclos de aprendizagem. São Paulo: Cortez, 2007.

OLIVEIRA, Dalila Andrade. Educação Básica: gestão do trabalbo e da pobrez̧a. 2.ed. Petrópolis, RJ: Vozes, 2010.

PARANÁ. Secretaria de Estado da Educação. Ensino fundamental de nove anos: orientações pedagógicas para os anos iniciais/autores: Angela Mari Gusso et al./ organizadores: Arleandra Cristina Talin do Amaral, Roseli Correia de Barros Casagrande, Viviane Chulek. -Curitiba, PR: Secretaria de Estado da Educação, 2010.

PARANÁ. Secretaria de Estado da Educação. Instrução Conjunta nº 02/2006. Estabelece normas para implantação do Ensino Fundamental de Nove Anos no Sistema estadual de Ensino. Curitiba, 2006.

PARANÁ. Conselho Estadual de Educação. Deliberação n 03/06. Normas para a implantação do Ensino Fundamental de 9 (nove) anos de duração no Sistema Estadual de Ensino do Estado do Paraná. Curitiba, 2006.

RIO GRANDE DO SUL. Conselho Estadual de Educação. Parecer $n^{\circ} 752$, de 26 de outubro de 2005. Manifesta-se sobre o ingresso obrigatório a partir dos 6 anos de idade no ensino fundamental de nove anos de duração. Determina procedimentos a serem adotados. 2005.

RIO GRANDE DO SUL. Conselho Estadual de Educação. Parecer $n^{\circ}$ 644, de 30 de agosto de 2006. Orienta o Sistema Estadual de Ensino sobre a ampliação do Ensino Fundamental para nove anos de duração. Porto Alegre, 2006a. 
RIO GRANDE DO SUL. Conselho Estadual de Educação. Resolução n 289, de 21 de setembro de 2006. Dispõe sobre o credenciamento e a autorização para o funcionamento do ensino fundamental de nove anos de duração no Sistema Estadual de Ensino, em decorrência da Lei federal n 11.274 , de 06 de fevereiro de 2006. Porto Alegre, 2006b.

RIO GRANDE DO SUL. Conselho Estadual de Educação. Parecer nº 194, de 28 de janeiro de 2011. Orienta o Sistema Estadual de Ensino sobre a organização curricular do Ensino Fundamental de nove anos, face ao disposto no Parecer CNE/CEB no 11/2010 e na Resolução $\mathrm{CNE} / \mathrm{CEB} \mathrm{n}^{\circ} 7 / 2010$, especificamente quanto à organização dos três anos iniciais do ensino fundamental. 2011.

RIO GRANDE DO SUL. Secretaria do Estado da Educação. Portaria n 151, de 13 de setembro de 2011. Porto alegre, 2011b.

SANTA CATARINA. Secretaria de Estado da Educação, Ciência e tecnologia. Diretrizes e orientações para subsidiar os encaminhamentos e o trabalho dos professores e gestores, em relação à questão dos nove anos do ensino fundamental. Florianópolis, $\mathrm{s} / \mathrm{d}$.

SANTA CATARINA. Secretaria de Estado da Educação, Ciência e Tecnologia. Portaria no 22, de 20 de novembro de 2006. Dispõe sobre a implantação do Ensino Fundamental de Nove Anos. Florianópolis, 2006a.

SANTA CATARINA. Secretaria de Estado da Educação, Ciência e tecnologia. Orientações para organização e funcionamento das unidades escolares de educação básica e profissional da rede pública estadual-2009. Florianópolis, 2009.

SANTA CATARINA. Secretaria de Estado da Educação. Orientação curricular com foco no que ensinar: conceitos e conteúdos para a Educação Básica - Documento Preliminar. SEE, Florianópolis, 2011.

SCHNEIDER, M.P.; DURLI, Z. Ensino fundamental de nove anos: aspectos legais e didático-pedagógicos. Roteiro. Joaçaba, v. 34, n. 2, p. 189-214, jul./dez. 2009a.

. O ensino fundamental é de nove anos: e agora? In. ANAIS... IX Congresso Nacional de Educação EDUCERE. PUC- Paraná, 2009b. Disponível em: <http:// www.nre.seed.pr.gov.br/cianorte/arquivos/File/PEDAGOGAS/NOVE_ANOS/ NOVEANOSEAGORA.pdf>. Acesso em: 20 jun. 2012.

. Propostas curriculares para o ensino fundamental de nove anos: multirregulações e a influência das avaliações em larga escala. Revista Teias. Rio de Janeiro, v. 13, n. 27, p. 177 190, jan./abr. 2012.

\section{NOTAS}

${ }^{1}$ Com a promulgação da Lei 12.796, de 4 de abril de 2013, a educação obrigatória e gratuita passou a ter 14 anos de duração, estendendo-se dos 4 (quatro) até os 17 (dezessete) anos de idade. ${ }^{2}$ Estudos realizados por Schneider e Durli (2009) evidenciam que, no ano de homologação da Lei 11.274/2006, que alterou a duração do ensino fundamental (de oito para nove anos), vários Estados brasileiros já praticavam algum tipo de ampliação da escolarização obrigatória. Como indicativo, citam que no ano de 2003 havia mais de 11 mil escolas de educação básica no Brasil ofertando o EF9A.

${ }^{3}$ As informações foram fornecidas por gestores das secretarias estaduais de ensino identificados no texto pelas siglas RSC (Resposta do Gestor da rede estadual de Santa 
Catarina), RPR (Resposta do Gestor da rede estadual do Paraná), RRS (Resposta do Gestor da rede estadual do Rio Grande do Sul).

${ }^{4} \mathrm{Na}$ análise do processo de constituição de uma política pública educacional, Ball (1994) defende a necessidade de considerar a existência de um ciclo contínuo de políticas constituído por cinco contextos. O primeiro deles compreende o contexto de influência, onde normalmente as políticas públicas são iniciadas. Em seguida vem o contexto de produção dos textos legais oficiais que representam a política. O terceiro é representado pelo contexto da prática, onde a política está sujeita a reinterpretações. Em quarto, temos o contexto dos resultados ou efeitos, onde as políticas são analisadas a partir de seus impactos e das interações com questões de justiça, igualdade e liberdade individual. Por fim, o quinto contexto é o da estratégia política e envolve a identificação das atividades sociais e políticas necessárias para fazer frente às desigualdade produzidas pela política. Uma análise pormenorizada desses contextos na abordagem do ciclo de políticas de Bowe e Ball pode ser encontrada em Mainardes (2006).

${ }^{5}$ No Estado do Paraná, o papel do CEE e SEE apresentou especificidade em relação aos demais Estados da Região Sul em função da universalização da municipalização das séries iniciais do EF.

${ }^{6}$ Parecer CEE 644, de 30 de agosto de 2006, Resolução CEE 288, de 21 de setembro de 2006, Resolução CEE 289, de 21 de setembro de 2006, Resolução CEE 289, de 21 de setembro de 2006, Parecer CEE 644, de 30 de agosto de 2006 (e muitos outros Pareceres nesse período), continuando a tratar das mesmas questões ainda em 2011 com a Resolução CEE 314, de 4 de maio de 2011.

${ }^{7}$ Dentre o conjunto de documentos produzido com a intenção de orientar redes de ensino e escolas sobre o processo de implantação, destacamos especialmente "Ensino Fundamental de nove anos: orientações para a inclusão das crianças de seis anos", produzido pelo MEC em 2006 e mencionado como referência pelas esferas estaduais dos Estados sulinos nas normatizações que tratam do EF9A.

Recebido: 14/01/2014

Aprovado: 21/07/2014

Contato:

Universidade Federal de Santa Catarina Centro de Educação CED Campus Universitário Trindade Florianopolis $|\mathrm{SC}|$ Brasil CEP 88.010-970 
